\title{
Citizen Aid, Social Media, and Brokerage after Disaster
}

Deirdre McKay ${ }^{a}$ and Padmapani Perez ${ }^{\mathrm{b}}$

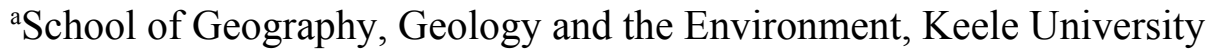

${ }^{\mathrm{b}}$ Institute of Arts and Sciences, Far Eastern University, Manila

William Smith Building

Keele University

Keele, Staffordshire, UK ST5 5BG

d.c.mckay@keele.ac.uk 


\title{
Citizen Aid, Social Media and Brokerage after Disaster
}

\author{
Abstract: \\ In a crisis, aid providers deliver humanitarian relief across a hierarchy of organisations where \\ influence and capacity map to their scale of operations (Fouksman, 2016; Mercer \& Green, \\ 2015). On the front lines of crises, 'citizen aid' is what small, local and informal groups offer to \\ fellow citizens. These citizen aid groups are well-networked in place and tend to work through \\ longstanding personal relationships (Fechter, in press; Sanchez et al., 2016). In the Philippines, \\ citizen aid groups frequently support their activities by documenting their work with photos of \\ beneficiaries to solicit donations from within the country and around the world across social \\ media platforms (Bonacker et al, 2017.) This paper builds on recent debates on brokerage \\ (Lindquist, 2015) to examine a case of citizen aid in the relief effort after Typhoon Haiyan (2013 \\ - 2017). We demonstrate how social media has produced new forms of brokerage shaped by \\ circulating images online. This kind of brokerage produced a layered network of brokers that \\ both shaped citizen aid efforts and created new channels for localising aid, enhancing the control \\ of citizen groups in the global Southern over humanitarian aid.
}

\section{Keywords:}

citizen aid; brokerage; humanitarian aid; social media; post-disaster relief; Typhoon Haiyan 


\section{Introduction: Citizen Aid and Brokerage}

In a crisis, aid providers deliver humanitarian relief across a hierarchy of organisations where influence and capacity map to their scale of operations (Fouksman, 2017; Mercer \& Green, 2015). On the front lines of crises, 'citizen aid' is what small, local and informal groups offer to fellow citizens. Citizen aid groups are tied to place and work through longstanding personal relationships (Fechter, in press; Sanchez et al., 2016). Increasingly, citizen aid groups support their activities by documenting their work with photos of beneficiaries to solicit donations across social media platforms (Bonacker et al, 2017.) Citizen aid groups' social media practice gives them a perceived 'reach' that enables them to become involved in a wider scope of relief effort (Dawes, 2017). In effect, these groups act as brokers in the humanitarian assistance landscape.

With the increasing pressure to localise aid (World Humanitarian Summit, 2016; Bonacker et al, 2017), citizen aid efforts could potentially become even more vital in humanitarian emergencies, it is important to understand the diversity of citizen aid and the range of actors involved.

Citizen participation in humanitarian assistance has most often been approached through the lens of volunteering (Laurie and Baillie Smith, 2017), with a focus on its benefits for volunteers and donors (e.g. Malkki, 2015). Studies of volunteering tend to privilege northern mobilities, tracing the movement of 'global citizens' from North to South, rather than focussing on South-South interactions. As Laurie and Baillie Smith (2017) argue, there are new volunteers and development actors in the global South, practising very different forms of career and life-making connected to their volunteering in humanitarian efforts. Rather than again 
reinscribing the problematics of the volunteering analysis Laurie and Baillie Smith try to deepen and complicate, here we approach citizen aid through the lens of brokerage.

There is a long tradition of considering development's intermediaries as brokers (e.g. Lewis and Mosse, 2006: 11 - 13; Hönke and Müller, 2018: 335-336) in development studies, building on an extensive literature in political anthropology (Lindquist, 2015). Brokers draw together and facilitate exchanges between disparate systems, peoples and spaces, acting to their own advantage whilst advancing the interests of others and generating value through their actions (Hilhorst, 2003). In development aid, brokers often act within established organisations and channels, at the edges of formal processes. Here, they extemporise, challenging existing scripts for behaviour and setting up new channels for resource and information flows in order to shape exchange relationships. Brokers prevail in spaces where a weak state cannot impose its own rationality on the recalcitrant local. Brokers of aid traditionally set up competing channels for flows of value, information or concern from global or national-level organisations into the local context in which they operate. They typically minimise the effects of attempts by these higher-level organisations to intervene in local relationships. Brokers instead control the local context by enlisting existing patron-client relationships and/or creating novel ones. There is a renewed interest in brokerage in the context of migration (Lindquist, 2015; Shrestha and Yeoh, 2018) that focusses largely on cash payments and accumulation of finance capital, but there is also a long tradition of brokerage accumulating - or reshaping and deploying - other forms of capital e.g. social, cultural or educational capital (e.g. Ortiga, 2018.) Here, we explore the ways that citizen aid brokerage across social media makes these forms of capital fungible, converting 
social capital expressed as social media 'shares' and 'likes' into donations and donations into patron-client exchange.

Brokers may attract and attempt to control clients by appropriating and redirecting resources, limiting their access to services, creating modes of preferential treatment, or refusing to enact policy directives, among other expressions of autonomy. Their autonomous action outside the existing norms of institutional conduct is key to brokers' operations. By working in their own interest to subvert the formal processes and regulations of aid governance, brokers remain powerful yet vulnerable. They can be accused of corruption and fraud and forced to respond to claims they have failed to deliver the results promised to both their donors and their beneficiaries. Where brokers' actions connect people across two or more complex systems of social relations - e.g. INGOs from the global North and local government officials in the global South - their actions can reveal how systems of governance and aid delivery function by demonstrating where those systems are dysfunctional (Wolff, 1956 in Lewis and Mosse, 2006: 12). Brokerage thrives where the business-as-usual mode of aid governance is not working, and this is particularly true of the context of urgent post-disaster relief efforts. In disaster relief, brokerage roles proliferate (e.g. Saban, 2015), filling in 'structural holes' in the disaster response.

By analysing citizen aid through the lens of ethnographic studies of brokerage developed in development anthropology, we show how citizen aid groups work at multiple scales in a cascade of brokerage relations to connect disparate groups, bringing together different logics, representations, meanings and materialities, and acting with autonomy as they deliver humanitarian assistance (Koster and van Leynseele, 2018). The rise of social media gives local 
citizen aid groups a new global reach and enables them to create new forms of brokerage that privilege local Southern control over resource flows from the global North. To make this argument we first outline our typology of citizen aid actors, then focus on one key actor to explore how citizen aid brokerage reveals this new global layering of relationships. While previous studies of development brokerage focus on translation (Lewis and Mosse, 2006), we find that the mediating role of images online shapes citizen aid brokerage relations.

\section{1 - Citizen Aid and Social Media: Typhoon Haiyan}

After Typhoon Haiyan (Yolanda) hit the Philippines in November 2013, the affordances of social media were key to the recovery effort but also shaped it in both negative and positive ways (Atienza et al, 2019; Eadie and Su, 2018; Ong and Combinido, 2017; Madianou et al, 2016). Our research extends our understanding of what is a rapidly changing aid interface by focussing on citizen aid groups as brokers in this context. We began by tracking the activities of citizen aid providers across Facebook and Twitter and assessed social media posts on Facebook and Twitter hashtagged Haiyan and Yolanda 2013. We then conducted semi-structured interviews during 2016 - 2017 with willing and extant groups, businesses, and organisations who had made these

posts back in 2013, discussing how they now considered social media had supported their aid activities. All these citizen aid groups had relied on volunteer staff who had left behind their everyday jobs in business, the academy, the arts, or the third sector to participate in the post-typhoon relief effort and supported their activities by raising funds and recruiting volunteers 
over social media. Having elicited their accounts of each group, its origins, efforts and post-disaster relief contribution, we then made site visits to conduct open-ended interviews with aid recipients and local government officials in their beneficiary communities. Our analysis triangulated between online posts and these two sets of interviews, seeking to identify the layered relationships between the ethics of producing and circulating social media visuals largely photographs - and the brokerage of humanitarian resource flows, usually in cash, but also in the form of social capital. All our respondents described this form of social capital in English as 'trust' and, for them, this term described ongoing, personal and dyadic exchange relation founded through reciprocal expressions of compassion and appreciation or gratitude (see Ong and Combinido, 2017).

Having determined that our focus would be to distinguish citizen efforts that relied on social media, rather than other forms of brokerage (see Saban, 2015), we classified our citizen aid actors in four broad categories as we encountered them through the hashtags we followed. The first category comprised Philippines-based companies or groups of volunteers who formed what were effectively new informal aid organisations. These groups geared up to deliver relief on the ground, switching from their day-to-day business to do predominantly short periods of relief work. Often the first groups on the ground in the affected areas after the typhoon, they temporarily shifted their activities from, for example, guiding sailing tours for tourists to delivering aid packages or from running a nursery school to operating a soup kitchen. They posted reports of their assessment and actions to social media for amplification. The second category were material and in-person responders. A global and diverse range of people who had some prior connection to affected areas either as tourists, out-migrants or through their client or 
customer base, these people contributed their own labour on the ground (if in the Philippines) or donated material resources in response to calls from the first group of citizen aid first responders, amplified by the third category. The third category is comprised of private individuals around the world who had access to social media and digital resources, with time, personal networks, and post-making skills. These online-only actors created channels for disaster response on social media platforms and then amplified posts to support the actions of others. The final category was made up of established development charities or NGOs active in other sectors who switched their focus to humanitarian relief work as a new activity. These development industry experts had often worked alongside groups in category one and sometimes collaborated, while their actions had also been amplified by people posting on social media in category three. There was, of course, lots of interaction between these categories and an individuals' actions meant they could have operated across two or more of them over the duration of the 2013 - 2017 disaster and recovery period. ${ }^{1}$

We selected as our case study for this paper a business from the first group - an eco-tourism provider on an island in the Southern Tagalog Region whom we call 'EcoTrek' which used social media to support first relief and then reconstruction efforts. New to both development aid and humanitarian relief and, initially, not well-networked in the development industry, EcoTrek quickly developed significant resource flows and an international scope for direct fund-raising. Despite the experience or formal positions of other aid efforts, it was the sheer scale of EcoTrek's fundraising that made it one of the most significant citizen aid efforts

${ }^{1}$ Both [author] and [author] operated in categories 2 and 3, reposting citizen aid posts and making cash donations. [Author] also donated items and sorting resources collected in Manila in support of citizen aid efforts on the island. She is herself a category 1 citizen aid worker, having organised relief after Typhoon Parma in 2009. 
we explored. In turn, EcoTrek's success in delivering citizen aid had deployed social media to create a bridge between disaster-affected villages and donors by expanding on their already-established global social media channel. As Eco-Trek's owner, Teddy, explained: “... we had... basically a logistics company... we have all these boats... we have all these connections with the villages. It was just perfect. It was just like typhoon, next day: carry on.

\section{But we can show it to people."}

EcoTrek's story demonstrates how citizen aid works through a new form of brokerage shaped by circulating images. Here, the action of mediated image and the ethics underpinning their creation and circulation depended on a layered network of brokers that both shaped citizen aid efforts and created new channels for localisation, potentially offering a replicable model that gives citizen groups in the global Southern more control over disaster relief. In what follows, we privilege the voices and interpretations of our Eco-Trek and community interviewees to establish how they, as organic intellectuals in the global South, and new to humanitarian relief and development more broadly, understood their citizen aid experience.

\section{1 - EcoTrek's story}

EcoTrek's proprietors and staff began to organise their online response shortly before Typhoon Haiyan entered the Philippine area of responsibility, posting images and text updates to Facebook. Initially, staff in the Philippines managed these posts, but this wasn't sustainable as they moved into managing on-the-ground first response and assessment efforts. Cheryl, a former intern then based in Europe, had set up a new relief-oriented EcoTrek Facebook page to support what was happening on the ground. EcoTrek's owners, Teddy and Victor, eventually delegated 
the task of managing Haiyan-related posts to her. Cheryl is Filipino, knew the island and was familiar with the operations of EcoTrek. She had strong off-line and online relationships with both Teddy and Victor and EcoTrek's former guests, both Filipino and European. Cheryl explained how her role emerged:

"EcoTrek...managed to take a boat around the islands and figure out the injuries, the losses, the needs.... And luckily, in the age of smartphones, they were also able to send pictures.... of what the villages actually looked like... And those very quickly went up online."

Working from Europe, Cheryl received these images and designed posts in English, trying to ensure that the images were published quickly and in chronological order. She documented EcoTrek's relief effort so that "you would see that this group is really putting their money where their mouth is...It was me being the communication link."

Cheryl thus brokered the posting of images, selecting those she thought would make the best posts for raising relief funds while also not undermining EcoTrek's longer-term interests in encouraging visitors to use their guided tour services. Within three days, Cheryl had over a thousand people following her page. Her initial followers, EcoTrek's former guests added from her personal profile and EcoTrek's corporate page, had reposted her posts to their own timelines and their 'friends' on Facebook had then shared them onwards. Cheryl explained: "even if someone can't donate, their likes, and their shares, and their comments - It helps. I mean, just the way the algorithms of Facebook are made, every like, every share kind of spreads it further and further." In establishing these networks, Facebook itself worked as a broker. 
Four days after Haiyan, Facebook's U.S.A. offices emailed to ask if they could help her. Facebook made a short video featuring Cheryl as a person in Europe helping with the Haiyan response in the Philippines. This was intended to publicise EcoTrek's relief efforts. The video described how Facebook helped Cheryl start the EcoTrek relief operation page. Cheryl described the video as 'all marketing' for Facebook, portraying the platform as facilitating humanitarian relief. The video marketed EcoTrek to a wider group of Facebook users who might consider donating to the Haiyan relief effort through citizen aid channels rather than via established INGOs. An employee from one of Facebook's European offices shared Cheryl's video on her own profile. Cheryl credited this personal 'share', combined with the wide circulation of her initial posts, for generating a large number of donations from Europe.

Facebook did not advise on the design of her EcoTrek posts. Instead, the EcoTrek team learned which images were most effective at generating donations by trial and error. Cheryl described it as “... learning by doing...You learn along the way how much attention and how many views each post gets..." Cheryl worked with Teddy, based in Manila, who followed the posts and provided feedback to Cheryl on the amounts of money arriving in EcoTrek's relief account and its origins. These images were, in the larger process of raising funds, securing supplies, and distributing aid, themselves acting as brokers. Cheryl used Facebook Analytics to see who responded to what kinds of posts and which posts appeared to correlate to surges in donations reported by Teddy. Teddy forwarded her selected images sent to him by MMS (mobile messaging service) from Victor and other EcoTrek staff in the field. When Cheryl noted that donors appeared more likely to donate money for a relief 'thing', she asked EcoTrek staff to organise more pictures of relief goods and packages. 
EcoTrek staff then took photographs in their beneficiary communities to demonstrate transparency and accountability to donors as aid was distributed. Victor recounted how the mediation of photographs rapidly generate cash donations for specific things:

"We report every step... taking photos of the shipment... of the sacks... of the tarp... People are asking [online] 'what do you need', and they [in the typhoon-hit areas] are saying "nails", and people on Facebook, they say 'okay $\$ 500$ '”

Since the EcoTrek team had no previous experience of humanitarian relief or development assistance, the idea that people were more likely to donate for concrete or identified things; not general "aid" but specific items, like nails and tarp for rebuilding, was a key insight. In response, Teddy designed their most successful donation-eliciting image, a photo of their basic relief goods package: “...Oh, they need a sack of rice, tarpaulin ... stuff like that... And I... laid it [all the goods] out on the table... like a viral shot... 65 Euros is enough of donation to get a fisherman's family back on their feet. 65 Euros, that's how much we needed [per donor] ... They [the Facebook audienceDM] loved it... it's a manageable sum and ... it's the people that actually trust you."

Teddy's final point here is an important point one: these donors were, by and large, people who had already had personal contact with EcoTrek's businesses, staff, and host communities in the Philippines before they donated. Other donations came via their personal networks, in a lateral expansion of trust relations: 
“The people that donated are people who's been on our trips. ...They've seen our communities.

So they're actually like oh, like 'Okay, these guys' And you know, they persuaded others to go and donate and don't go to the big ones [NGOs and INGOs] because, you know, but I think there was a trust there as well that we... tell them 'this is what we're doing'... Trust."

Online, EcoTrek established this trust by showing people aid delivered, keeping up a feed of carefully selected images from recipient communities. This sequence of curated images concealed other frictions in brokerage relations, of course, but the lessons on brokerage here are made evident by the stories of these images, themselves working as brokers.

\subsection{Images as brokers}

EcoTrek staff produced, collected and selected images with their potential to elicit donations in mind. Circulation of these images, often with unanticipated meanings ascribed to them, elicited and channelled donations to citizen aid. Donations elicited in response to images expanded EcoTrek's control over flows of cash, material resources and channels of distribution from their base of operations in Manila and the island, out into beneficiary communities. In this way, the space of citizen aid was comprised by layers of brokerage where images produced and attached value to other brokers. For those who saw and 'liked' or 'shared' EcoTrek Facebook posts, the images accumulated digital social capital, enhancing their profile and on-line reputation as humanitarian and knowledgeable. EcoTrek sought to convert and channel this value into donations while also promoting their core tourism business.

EcoTrek staff were very aware that they needed to protect the long-term interests of their tourism business at the same time as eliciting aid. So, they tried to avoid taking and circulating 
images that replicated the usual visual tropes other aid-delivering groups were circulating during the post-Haiyan crisis. These more familiar media photos tended to focus on human suffering, competition and chaos, and mourning (Ong et al, 2015; Ong and Combinido, 2017). Cheryl explained EcoTrek circulation of more positive images of recovery as an effect of both 'culture' and the problematic performance of gratitude (Ong et al, 2015) of their beneficiaries for the aid they received. Cheryl recalled the reflective process that shaped her posts:

"And at some point, we were like, 'well, it's all so much drama', but when in fact, actually, the point of our page is to alleviate this drama... We weren't saying, you know, 'Donate your money because these people are in crisis.' We were saying, 'Hey, look at these families smiling about the bag of rice they just got. Let's help another one."”

Staff members taking and selecting these photographs that brokered aid donation were brokers in their own right, both individually and collectively, for the tourism industry and broader economy on the island. EcoTrek prioritised what they had assessed as the longer-term recovery needs of their target communities in the affected areas. For this reason, they consciously chose to challenge what they saw as dominant representations of post-disaster geographies and affects on social media in order to sustain tourism Victor and Teddy and Cheryl all told us they had selected images that would help to sustain the tourism industry. Teddy explained:

'I posted about the beauty of [the island] and it was more promotional. It's still beautiful. Because people are like.... 'I don't see how I can come on holiday, with total devastation and people...dying.' [I showed] it's not like that...Us, we are a tourism business; we need visitors. ,", 
EcoTrek circulated images that reflected that its 'currency' of operation (in Teddy's terms) is not 'followers' or virtual acknowledgement or appreciation but actual paying customers on the ground. So here we see the potential exploitation and altruistic aspects of brokerage combined. The images themselves and the EcoTrek staff strove to produce respectful and positive representations of affected communities while simultaneously gearing these posts towards generating donations and sustaining their business.

Images also brokered EcoTrek's claims to be trustworthy and effective. Staff generated images designed to ensure that donors could see the aid 'loop' (from donation to delivery and impacts) being closed on social media. These images were equally Janus-faced in their brokerage of trust. They may have been staged and inaccurate or set up via problematic patronage or representative of only partial success, but these images circulated to Facebook as evidence ('receipts' in Victor's terms, below) of aid delivery and shored up trust. EcoTrek deployed images to broker the flows of aid in four ways: images acted as information in themselves; images triggered action (donate, help, spread the word); images reported the outcomes of donations; and images gave evidence of proof of delivery and so by extension, accountability. This was not all images brokered, however; they were also brokering new kinds of North-South relationships within the geopolitics of aid.

EcoTrek's autonomy as a citizen aid group enabled them to develop an ethos around social media images where nationals apparently from 'donor nations' never featured prominently in their posts. Where non-Filipinos appeared at all, it was eyes facing forward, gaze directed away from the camera, carrying boxes of donations under the direction of EcoTrek's Filipino staff members. While some of EcoTrek's European guests who were out on their cruises at the 
time of the typhoon stayed on to help, another group of tourists stranded on the island also showed up to volunteer. Victor wrote to all the people who had cruises booked after Haiyan and explained that there would be no cancellations, but they should come, keep the economy running, and help in the relief effort by offloading relief goods from their cruise boats. These volunteers were not running the relief operations or posting to the Facebook page. Thus, unlike the more familiar story of volunteering or voluntourism, volunteer's accounts of transformative experience etc. were not shared across EcoTrek's social media at all. EcoTrek thus ensured their efforts were globally represented as 'South-South' aid, supported by donations from the global North they directed.

Autonomy as aid brokers also enabled EcoTrek to speak back to donors about global expectations for accountability and transparency, again using social media images to broker trust (or not.) EcoTrek found donors' requests for receipts for their donations naïve. Their status as a citizen aid initiative, not a registered charity or NGO enabled their efficient, direct approach. Teddy explained this in our interview by responding to an imaginary donor:

“...... if you send it to us, you have to trust where it's going. If you want me to track all our bank records, find your surname and find out how much and send you an email to confirm that we got that, that's what creates the 45\% administration fee that you're complaining about with Red Cross! If you trust us, then we cut out the admin and that [donation] goes directly to these people." 
Instead, as Victor explained in an overall summary of the lessons learned from their aid operation, the images EcoTrek 'reported' on social media served as receipts in themselves, showing how donations were converted to goods and delivered:

"Be an on the ground partner and use our logistics... For a fixed period... two weeks, three weeks. Get people up on their feet. Just short-term...Our report is the receipt. That's it. So, we don't have to do... all the administrative work."

Overall, EcoTrek considered their relief effort a success. The images deployed during the relief effort brought them global visibility as a socially-conscious business. In itself, the disaster response also bolstered local relationships: "People saw that it was genuine... it wasn't just a business for ourselves. We did actually... care."

\section{3 - Mediating trust}

EcoTrek's staff drew on their personal social networks of employees, current guests and previous guests, and the labour of volunteers, both local and international, who were recruited through their extended personal networks. This is the key characteristic that made the effort citizen aid. While the relief EcoTrek provided used the logistics capabilities and infrastructure of the business, it would not have been successful if it had not also incorporated this much wider group of people working in an expanded number of physical world and online sites. Cheryl in Europe and her Facebook networks were vital to the ability of teams on EcoTrek's boats who were carrying aid onshore in remote fishing settlements and vice versa. What made these aid relationships different from other digitally-mediated kinds of aid donation was that they depended on trust initially built through off-line, real-world encounters that were then activated 
online and used to further elicit aid donations from others. In this respect, EcoTrek is not a classic digital or online aid broker, or even an entirely 'entrepreneurial broker' (Saban, 2015). Their donors were people who had themselves - or via someone they knew or knew of and trusted - encountered the company's staff face-to-face and seen their community beneficiaries or villages like them - first-hand on one of their cruises. Though EcoTrek's images suggest a comparatively seamless flow of aid from donors on social media to village recipients based on trust, that account necessarily glossed over some key points of friction.

Exploring these frictions tells us more about the characteristics of mediated citizen aid and the layering of brokerage. The key question is not whether EcoTrek was a citizen aid operation OR a broker, but how it combined aspects of both functions and identities and what that then tells us about the space of humanitarian aid. Underpinning the images on which their efforts depended, EcoTrek showed different faces towards donors, towards local government and communities and to the broader aid community. These apparently contradictory relations reveal how effective EcoTrek was at negotiating brokerage. While claiming to be a maverick operation that broke with local protocols and moved away from established resource flows and politics, EcoTrek was a savvy local actor, frequently able to mobilise local patronage relations informally to garner support for their initiatives. While this strategy could be exploitative, it was generally interpreted as a benign necessity. EcoTrek staff felt that the effectiveness of their overall operation was based on an ethic of altruistic care and any frictions arising were the result of their commitment to expediency in delivery, rather than explicit attempts to channel and control resources and establish political influence amongst their beneficiaries. EcoTrek was not always 
successful in controlling local perceptions but remained a broadly respected actor. This trust was negotiated at three different scales.

\subsection{By expanding up and out}

One mark of EcoTrek's success as an aid operation was the way that the trust relationships it built at the local level cascaded up humanitarian relief hierarchy of organisations towards national NGOs and local government relief efforts. Because EcoTrek were first on the ground and established a visible online presence very rapidly, it had credibility at the local level and on social media. EcoTrek's high profile online led to it becoming a formal - and thus trusted - local partner for several smaller Filipino and international NGOs, the Catholic church (see Cornelio and Kuah-Pearce, 2015), and the Local Government Units in some target communities. Several national-level NGOs chose to course their relief goods/donations through EcoTrek because they saw - online - how EcoTrek was working with long-established local relationships and performing accountability.

EcoTrek maintained a degree of autonomy in these relationships, even where activities were delegated to them by other donors and humanitarian actors. They refused to partner with NGOs that wanted to offload resources and make EcoTrek staff do the groundwork of locating recipients for what were inappropriate donations. EcoTrek also refused to do monitoring of distribution channels and to distribute goods that had political party logos on them and, doing so, support particular factions in provincial and national politics. EcoTrek could refuse these tasks 
because of their citizen aid status; delivering aid or seeking grants for development projects would never be their core business.

Social media enabled EcoTrek as a citizen aid group at global scale by a variety of citizen aid actors, joining loose and informal global knowledge networks. Experienced people from other citizen aid relief operations saw their Facebook posts circulating and got in touch. Teddy recounted how the most useful advice on structuring their relief effort were comments he received unsolicited, via email, on Facebook. A Swedish citizen aid worker who had worked in Thailand after the 2004 tsunami had seen one of Cheryl's Facebook posts and wrote to advise how EcoTrek should handle requests to donate money and/or volunteer: “...quickly write a little e-mail saying: if you want to help, donate. And give them a bank account. The peek will only come once. It won't come back. So, you got to catch it straight away.... you're gonna get a lot of offers for help, ... But don't accept them, if... people [f***ing] flying over there to paint people's houses and all this $b^{* * * * * * t . . . ~ G o ~ g i v e ~[t h e ~ f u n d s ~ r a i s e d] ~ t o ~}$ the beneficiaries as soon as possible 'cause after that you get bogged down in the politics of it."

\subsection{By remaining relatively invisible to government}

Avoiding getting bogged down in local aid politics became key to EcoTrek's aid strategy. Their activities both competed with and complemented other kinds of aid in a complex local humanitarian ecology. The donations EcoTrek distributed were based on personal trust between their business and their donors and, because this relief relied on flows of private monies, EcoTrek could circumvent various forms of bureaucracy governing large INGO and government aid distribution on the island. This, in turn, made their activities comparatively less visible to 
local government than those of large charities and NGOs like the Red Cross and Oxfam that had formal collaboration agreements in place. EcoTrek could often get their aid in first, long before other actors had secured the requisite government approvals and resources. Occupying this space meant that EcoTrek avoided getting bogged down but it also made them somewhat invisible to local government.

In interviews with Local Government officials at the municipal level in recipient communities, we found a notable lack of awareness of citizen aid activities after Haiyan, including those of EcoTrek. In one municipality where EcoTrek had operated, we consulted the new municipal Disaster Risk Reduction Management plan and noted it did not include volunteers or citizen aid groups. Our interviewees there explained that they saw no need to include them and that citizen groups can/should continue to operate as they can. The local government offices across the island more widely appeared to have limited or no purview over citizen aid. Instead, local government offices had positioned themselves as aid brokers for national government and national and international NGOs, with elected officials using their own personal networks with another set of local-level brokers to channel resources received from national government and international donors (James, 2018). These local officials and brokers were in established local patronage networks where their own interests might compete with the activities of citizen aid groups. When asked specifically about the use of social media to mobilize resources after Haiyan, our local government interviewees repeatedly described citizen aid as best left to operate independently and social media as being largely beyond their area of concern. Government officials continually described relief efforts led by citizen aid as "kanya-kanya," or to each his own and noted that 'some people' came to the Local Government Unit [usually Barangay Hall or 
Municipal Hall] offices simply to inform them that they were doing their own relief work. Our various government interviewees did not grasp the scope and scale of the international fund-raising operations or the local activities of groups such as EcoTrek, who had handled many tens of thousands of dollars of aid donations - likely just as much, if not more money than had come to the Local Government-brokered relief effort.

In their relief efforts, the citizen aid groups we interviewed reported they had avoided local government except where necessary or only to the extent of making courtesy calls. EcoTrek found local government requirements obstructive and collaboration difficult. For example, they encountered a complex local authorisation process required to borrow a government boat (that was not being used at the time) to deliver relief goods. The perception was that keeping a government boat docked and restricting its use for disaster response at the time of need was unethical.

Victor, EcoTrek's owner, saw this as demonstrating how citizen aid ethics are based on personal trust in a way that is incompatible with the impersonal bureaucratic ethos that defined local government regulation: “...we're not... choked by any bureaucracy... I think it's a trust thing. It's much more of a, 'I'll give it to you personally. I don't care what you gonna use it for. '... But I know what you do." The relationships between citizen aid groups and local government were characterised by occasional collaboration but significant evasion.

Autonomy, global networks and lack of local visibility created a particular niche for citizen aid in the relief effort. Following EcoTrek's model, if these groups performed their accountability online, in a combination of posts that gave qualitative and quantitative evidence for their effective distribution of donated resources, they did not meet accepted aid industry 
standards. Citizen aid's inability to produce these key audit and accountability measures in turn limited the scale and scope of citizen aid actions. Funds donated by corporations who required a charitable donation receipt remained inaccessible to them, as did funds flowing from INGOs who required proper accounting reports, not social media posts. What EcoTrek shows us is how citizen aid groups' commitment to flexible informality drove them towards more social media fundraising from private individuals in their international networks. Their trust-based and dyadic approach developed online then produced a horizontal rather than vertical flow of humanitarian aid and, arguably, meant that they were not in competition with other national and international fund-raising efforts at the larger-scale donor level. Since they were not, in fact, competing with what local government aid brokers could offer after Haiyan, they were thus largely treated as irrelevant to officials' interests.

\subsection{By building trust with local communities}

Trust in local government was not high among many local community members in the typhoon-affected areas. They did not trust that their local government officials had provided aid when it had become available. Instead, they contrasted EcoTrek's aid to their experience of aid channelled through local government, which they considered to take too long and to be corrupt in the delivery and distribution process. Those who had successfully accessed local government aid complained about the layers of bureaucracy surrounding access to official national government relief goods and funds that should have been distributed via local government. Asked how aid delivery could improve, community interviewees answered unanimously: "direkta sa tao ang bigay." [Give directly to the people.] They observed that it was either groups like EcoTrek's or 
organizations like Red Cross - which had an extensive and high-profile local presence - that had bothered to come directly to the grassroots level and give aid directly.

'Giving directly' was not necessarily so direct. Despite their rhetoric, EcoTrek was not able to keep local government interests entirely at a distance. EcoTrek did end up relying on local elected leaders at the Barangay (village) level for the continued distribution of their post-disaster assistance. They thus channelled the aid they brokered through an even more local group of brokers they had selected from amongst elected leaders, wealthy or prominent local households, school teachers, and other public officials. Though EcoTrek did not favour working formally with elected officials, they ended up working with one in an informal capacity, relying on the patronage networks of the family of a Barangay Councillor to distribute some of their 'second wave' of relief goods. Not surprisingly, this family gave away the goods to people others perceived as their political clients, rather than those in most need of support. However, when compared to similar local government aid channels where aid got stuck in the Municipal Hall and never made it out to the villages, our interviewees found even this arrangement to be more accessible and transparent.

Here, we see that citizen aid cannot always transcend the established forms of brokerage already at play in beneficiary communities. Where 'small-time leaders or low-level civil servants seek support among those unable to act on their own' by exchanging goods or cash for political legitimacy (James, 2018), aid goods will always be folded into these exchanges. However, the village level approach meant local residents were disposed to see EcoTrek's activities as being more easily held to account than those of the local government officials operating at the next scale up - the municipality. 
Because of EcoTrek's comparative success in reaching the local, those who had been aid recipients tended to forget that EcoTrek's efforts were shaped by the owners of a business. Instead, in their eyes, EcoTrek had become a kind of charitable organisation, and community members frequently discussed EcoTrek as if it were a formally registered NGO, which it was not. They told us that NGOs worked better than the government, because they were faster and came directly to the people, then offered EcoTrek as an example. So, one effect of EcoTrek's successes as a citizen aid broker was to shore up a pre-existing mistrust for government efforts in humanitarian aid. Of course, this claim to greater trust and influence on local communities is a comparative one. There's good evidence that EcoTrek also struggled, as brokers do, to establish itself as a trusted donor and create the kinds of client-patronage networks that would deliver a sustainable economic recovery over the longer term. The problems they faced were due to context and competition from other aid donors.

3.3.1 Trust, failure, and refusal. EcoTrek was delivering aid to coastal settlements on comparatively remote islands where people depend on fishing as their main source of livelihood. They responded to the typhoon by landing boats in coastal areas without telecommunications and with no means of contacting national relief efforts. The first wave of aid that EcoTrek brought came as a response to immediate needs: potable water, food, tarpaulins for temporary shelter, and materials needed to rebuild homes.

EcoTrek's surplus of funds generated via social media let them extend their efforts beyond immediate relief and move into rebuilding and rehabilitation. Seeking to contribute to long-term economic recovery, EcoTrek commissioned and donated fibreglass fishing boats to 
fishing families who had lost their boats. These donated boats weren't immediately put to use in fishing. Recipients did not immediately trust the new material. Instead, the boats were left on shore and some eventually became planters for vegetables. Seeing this, EcoTrek decided to take the donated boats back from their recipients. As a citizen aid group, EcoTrek did not have to account to donors higher in the aid hierarchy for this apparent failure in their strategy. Instead, Victor set out the reasons for the boat recall on a social media post under a photo of a fibreglass boat full of soil and greens. He recounted:

“...we pulled [the boats], it's transparent. ... if that's a big organization, why would you pull that boat out if they're not using it in the village? That's causing problems in the relationship... But we just want to make it work 'cause we know that it took us three months to make those boats and how much, like millions, that we spent on those boats. And if you're gonna plant pechay [cabbage] in it: 'NO'! There's much more passion in what we do than - [than just handing things out]."

Some months later, fishing households became interested in trying out the boats. EcoTrek then loaned out boats for one-third of their cost (PHP 6,000), arranging for the debts to be collected by the boat recipients' Barangay (village) Council. Barangay Councils were free to use the funds collected for their own projects, as long as they informed EcoTrek about what they had done with the money. Here, EcoTrek was not necessarily setting out to undermine local government authority but attempting to work with the most local and basic political unit and control development efforts longer term. The problem with offering fishing household the replacement boats had been the timing. Victor: “...around December [2013], [the island] was 
flooded by people giving them things, throwing them money... already people offering to re-build their house because they have these ideas..."

Even as their boat project faltered, EcoTrek continually refused to participate in recovery initiatives they felt were neo-colonial and/or did not fit with the existing livelihoods of affected communities. Their staff were particularly scathing about ill-considered but well-meaning approaches from international donors. Victor explained:

“if they say, 'Oh no, we have a Danish architect.' No. $F^{* *} k$ your Danish architect. They don't know. 'We have a very famous Danish architect who's designing sustainable...' Yeah, but he doesn't f**ng know the island, so, no."

It is clear EcoTrek staff resented the distractions that international donations of flashy housing projects and inappropriate gifts of food entailed. They decided to use the surplus remaining from their relief campaign to set up a charitable foundation attached to the business and hire development professionals to scope and identify new collaborative projects across their area of operations in the Southern Tagalog region. EcoTrek now greets all its tourist clients and new staff with the story of EcoTrek's contribution to the recovery after Typhoon Haiyan and how the costs of their tour also support the projects of this foundation. Teddy explained: "We think long-term, and it's really 'no hand-outs'. Don't give anything on the plate but run a company. Now we're in a mix of, is it a foundation? Is it social enterprise?"

For EcoTrek, participating in the relief effort as a citizen aid group transformed their business from one with a social ethic into a social enterprise that supports local development directly. This shift represents an extension of their underlying ethos into new activities. Setting 
up the foundation - that would operate as a registered charity - was the evident ethical choice for them to make in order to act responsibly with the unanticipated windfall generated by their successful social media strategy.

\section{Conclusion -}

After Haiyan, EcoTrek acted with altruism and furthered their long-term interests by deploying imagery of, and thus creating online narratives about, their beneficiaries. We would expect this of brokers. What is new and noteworthy in their brokerage experience is the way social media proliferated the number of global/external brokers EcoTrek could bring under their partial control. Brokers here were not just human actors, but images, platforms and algorithms - these actants can operate in unintended ways that their human originators have not foreseen, creating their own brokerage effects. What we have presented as the story of Eco-Trek's relief effort is best understood as a layering of interdependent brokerage activities that created a global assemblage of brokerage. This aid assemblage was - perhaps strategically - least visible at the scale of local and provincial government where most other aid was channelled and controlled. Globally, however, it had powerful effects in its performative impact on the locus control over resource, representations and narratives of humanitarian aid remaining in the hands of actors from the global South.

For Eco-Trek, social media not only increased their autonomy as brokers, it gave them a particular kind of capital - not just financial but moral. Accumulating this trust and respect on the basis of their local knowledge and trusted status then enabled them to define their own scope of 
action and defend their values. These values, they indicated, privileged South-South solidarity and service, based on an ethic of compassion and processes of sustaining trust, rather than seeking approval of international donors, other aid actors, local government, or potential volunteers. Social media allowed them to control their representation of themselves as a Philippine business in touch with on-the-ground realities, engaged with local communities, knowledgeable of the area, and very mobile. This meant that international participation was downplayed in the sense that the quick recovery they were portraying on the ground was not thanks to aid and aid workers from the global North, but to local efforts and resilience.

Social media thus created new sites for and forms of brokerage. Where these new aid brokers fit in the shifting patterns in the overall ecology of aid is still being negotiated with the push towards localisation (Bonacker et al, 2017). It's clear, however, that many people in the Philippines trust these citizen aid groups more than local government or larger donors (Ong and Combinido, 2017), in terms of their local knowledge and their perceived responsiveness and transparency. At a moment when Facebook has been widely discredited for facilitating and profiting from political interference, not least in the election of Duterte in the Philippines (Ong and Cabanes, 2017; McKay, 2018), it is important to recognise that the affordances of the platform for humanitarian relief have become vital to this expanded form of citizen participation in disaster recovery operations. This kind of citizen aid may be curtailed or undermined by social media's problematic entanglements with political manipulation if the platform broker's brand 'Facebook' is not replaced by other, less exploitative, global information brokerage utilities. Equally, the image production strategies and ethics citizen aid groups develop and deploy will be something to which they will have to pay closer attention, lest they lose the trust of beneficiaries 
and donors alike. The necessary but ambivalent relationships as we would expect from brokerage are being stretched thin and, in some ways, potentially made more transparent with online visibility.

EcoTrek reveals how social media enabled an upward cascade of brokerage relations, facilitated by its global reach. As brokers, EcoTrek created the social and political space for their actions by meeting immediate needs. EcoTrek didn’t necessarily want to establish formal relationships but the reputation they had established effectively opened up the 'invited spaces' of formal partnerships with government and registered NGOs to them. Nonetheless, they then met with resistance because they refused to change the way they operated. So, as we would expect for brokers, their liaison or co-ordination with government units or registered NGOs remained weak and highly problematic. Though EcoTrek did go on to set up a charitable foundation, that foundation was not staffed by the same staff members who organised and delivered the post-Haiyan relief. For individual staff members who had been involved in the relief effort, their aid broker roles did not lead them on to careers in humanitarian or development work. Instead, citizen aid workers returned to their normal occupations and working lives but were working within a business that had adopted a different ethic in its operations. EcoTrek remained a business but recast itself as a social enterprise that would advocate for a particular vision of localising development. Rather than producing a competing set of patronage networks in order to undermine older forms of local government legitimacy, we found EcoTrek slotted itself into a comparatively complementary space in the aid ecology. This suggested citizen aid groups working across social media do not pose a direct threat to the existing hierarchy of aid provision 
through government channels, but supplement and diversify it, filling in some of the 'structural holes' (Saban, 2015) that riddle the post-disaster recovery aid ecology.

It's evident that the brokerage activities of social media images here enhanced relations of trust between local actors and communities. Circulating images enabled citizen aid brokers coordinating across multiple sites to assemble global resource packages of materials, skills and knowledge incredibly quickly and efficiently. It offered personal, tailored and rapid responses to queries about needs and the routing of material resources. It was this performance of speed and targeting that increased trust which threatened to subvert the authority and position of other, more traditional, aid brokers, because local trust in brokers was directly related to their perceived responsiveness to immediate recovery needs (Ong and Combinido, 2017). Where government aid was perceived as slow to arrive and not always what was needed, EcoTrek was speedy and responsive to local needs. Aid brokerage here was not simply about accepting and distributing money, but trust. This trust was built by establishing integrity - delivering what was promised and developing legitimacy by transparently performing accountability to donors and communities for the funds raised accompanied by easily-understood and convincing explanations of the group's actions. This ongoing process of renewing and expanding trust built EcoTrek's 'brand' reputation and, while it depended largely on interpersonal relationships within beneficiary communities, its external elements relied almost entirely on social media. Thus, social media made the cash value of the funds raised by EcoTrek fungible, turning donations into other forms of value, particularly the reputational or social capital of the business at both local and global scales, something vital to sustain an eco-tourism business that operates both internationally and very locally. 
Finally, this case has implications for the space of humanitarian aid. It demonstrates how comparatively inexperienced and improvisational citizen aid brokers can use the economic bricolage inherent in online and long-distance fundraising efforts to powerful effects yet are typically left out of discussions on 'local aid' and disaster-preparedness or response plans because they are informal and unregistered. Because we have begun to see evidence that these same groups or similar will re-organise and re-emerge in response to new disasters, changes in practice are needed to create invited spaces where these groups can engage effectively with emergency preparedness and planning.

\section{References}

Atienza, M., Eadie, P. and Tan-Mullins, M. 2019. Urban Poverty in the Wake of Environmental Disaster: Rehabilitation, Resilience and Typhoon Haiyan (Yolanda). London: Routledge.

World Humanitarian Summit, 2016. Financing: Investing in Humanity. http://bit.ly/1NVKEbR 
Bonacker, T., von Heusinger, J., and Zimmer, K., eds., 2017. Localization in development aid: how global institutions enter local lifeworlds. Abingdon: Routledge.

Cornelio, J. and Kuah-Pearce, K. 2015. Religious philanthropy in Asia. Asian Journal of Social Science 43:349-55.

Dawes, M., 2017. H2H - a new formula for aid? CDAC http://bit.ly/2nXubMB

Eadie, P. and Su, Y. 2018. Post-disaster social capital: trust, equity, bayanihan and Typhoon Yolanda. Disaster Prevention and Management 27(3): 334-345

Fechter, A-M., 2019. Brokering transnational flows of care: the case of citizen aid. Ethnos (in press)

Fouksman, E., 2017. Civil society knowledge networks: how international development institutions reshape the geography of knowledge. Third World Quarterly 38(8):

1847-1872. DOI: $10.1080 / 01436597.2016 .1233490$

Hilhorst, D. 2003. The Real World of NGOs: Discourses, diversity, and development. Quezon City: Ateneo de Manila University Press. 
Hönke, J. and Müller, M. 2018. Brokerage, intermediation, translation. In Draude, A., Börzel, R., and Risse, T., The Oxford Handbook of Governance and Limited Statehood. Oxford: Oxford University Press, pp 335-352.

James, D. 2018. Mediating indebtedness in South Africa. Ethnos 83(5): 841-831.

DOI: $10.1080 / 00141844.2017 .1362450$

Jensen, S. 2018. Epilogue: brokers - pawns, disruptors, assemblers. Ethnos 83(5): 888-891.

DOI: $10.1080 / 00141844.2017 .1362455$

Koster, M. and van Leynseele, Y. 2018. Brokers as Assemblers: Studying Development Through the Lens of Brokerage. Ethnos, 83(5): 803-813. DOI: 10.1080/00141844.2017.1362451

Laurie, N. and Baillie-Smith, M. 2018. Unsettling geographies of volunteering and development. Transactions of the Institute of British Geographers 43: 95 - 109.

Lindquist, J. 2015. Brokers and brokerage, Anthropology of. In International Encyclopaedia of Social and Behaviour Science, edited by James D Wright, $2^{\text {nd }}$ ed. 870-874. Amsterdam: Elsevier.

Lewis, D. and Mosse, D. 2006. Development Brokers and Translators: The Ethnography of Aid and Agencies. Bloomfield, CT: Kumarian Press. 
Madianou, M., Ong, J., Longboan, L., and Cornelio, J. 2016. The appearance of accountability: communication technologies and power asymmetries in humanitarian aid and disaster recovery Journal of Communication 66(6): 960-981.

McKay, D. 2017. The virtual meets reality: the policy implications of E-diasporas. A report prepared for the Australian Strategic Policy Institute. Available at:

https://s3-ap-southeast-2.amazonaws.com/ad-aspi/2017-12/SR113\%20E-Diasporas.pdf?0aaNZ8a 8Ouxtb6mAjDdcYx5QALbkNjTu

Malkki, L. 2015. The need to help: the domestic arts of international humanitarianism. Durham, NC: Duke University Press.

Mercer C. and Green, M., 2013. Making civil society work. Geoforum 45, pp. 106-15.

Ong, J. and Cabanes, J. 2017. Architects of Networked Disinformation. A report prepared for the Newton Fund Tech4Dev Network. Available at: http://newtontechfordev.com/wp-content/uploads/2018/02/ARCHITECTS-OF-NETWORKEDDISINFORMATION-FULL-REPORT.pdf

Ong, J. and Combinido, P. 2017. Silenced in the Aid Interface: Responsible Brokerage and Its Obstacles in Humanitarian Interventions. Philippine Sociological Review 65: 39-64. 
Ong, J., Flores, J, and Combinido, P. 2015. Obliged to be Grateful: How local communities experienced humanitarian actors in the Haiyan response. A report prepared for Plan International. Available at:

https://ra.le.ac.uk/bitstream/2381/33421/2/Obliged\%20to\%20Be\%20Grateful\%20-\%20final.pdf

Ortiga, Y. 2018. Education as early stage brokerage: cooling out aspiring migrants for the global hotel industry. Pacific Affairs 91(4): 717-738.

Saban, L. 2015. Entrepreneurial Brokers in Disaster Response Network in Typhoon Haiyan in the Philippines, Public Management Review, 17(10): 1496-1517. DOI:

$10.1080 / 14719037.2014 .943271$

Sanchez, M., Perez, P, \& Perez, F., 2016. The scars of good intentions. In Flor, A. et al, eds. Resilience and Sustainability. Baguio: University of the Philippines, Baguio City. Pp. TBA.

Shrestha, T. and Yeoh, B. 2018. Introduction: practices of brokerage in the making of migration infrastructures in Asia. Pacific Affairs 91(4): 663-672. 